\title{
Acceleration of Košice-Airport-Bound Shuttle Boarding
}

\author{
Gabriel Fedorko ${ }^{1, *}$, Vieroslav Molnár ${ }^{2}$, and Lenka Lacková ${ }^{1}$ \\ ${ }^{1}$ Technical University of Košice, F BERG, Logistics Department, Park Komenského 14, 04001 \\ Košice, Slovakia \\ ${ }^{2}$ Technical University of Košice, FVT, Department of Computer Aided Manufacturing Technologies, \\ Bayerova 1, 08001 Prešov, Slovakia
}

\begin{abstract}
The present paper deals with a more efficient way of transporting passengers to the Košice airport, which will result in an overall acceleration of traffic and a reduced transportation time. Based on the actual time of boarding at specific stops on the given route, a simulation was performed through the Extend Simulation Program. Through simulating further two suggested modifications in the placement of ticket validators in the vehicle and through using the same input data, the passenger boarding time has been reduced. The data in the models can be modified and altered according to various requirements and criteria. Based on the results of the simulation, it was possible to propose a more efficient solution to accelerating the public transport to the Košice airport.
\end{abstract}

\section{Introduction}

Urban public transport is a very important feature of every city. For many commuters, it is the fastest means of transport; however the number of passengers using it is constantly decreasing [1]. The measuring and monitoring of the performance, the quality of service, the pricing and evaluating of integrated bus transportation was dealt with by Hensher [2]. Despite the increase in the quality of services provided by city transport companies, the number of cars has considerably increased and commuters tend to opt for public transport less frequently [3]. This has resulted in reducing the road permeability and in roads becoming more congested, as well as in urban public transport being delayed. Rohani et al. [4] explored the type of bus transport, the quality of bus services that influence a passenger's decision, as well as a bus operator's and a driver's roles. A wide range of factors were studied by Paulley et al. [5], who focussed on the impact of fare, service quality, revenues and vehicle ownership, as well as the factors affecting the demand for public transport. The existing public transport systems in Germany have reduced their costs by organizational restructuring and by outsourcing newly established subsidiaries [6].

Understanding the motivation of passengers' behavior in public transport is very important because customer loyalty is viewed upon as the chief determinant of long-term

\footnotetext{
*Corresponding author: gabriel.fedorko@tuke.sk
} 
financial performance. Lai and Chen [7] point to such behavior and examine the relationship between passengers' behavior and a variety factors affecting it.

Determining the optimal number of stops and their location in places in which delays occur and assessing the transport performance impacts by simulation are dealt with by Cats et al. [8]. The modeling of passenger flows in public transport was dealt with by Daamen $[9]$.

The present paper points to an effective solution to the acceleration of passenger transport to the Košice Airport and the possibility of its verification by simulation models.

\section{Defining the Problem}

In the buses operating on the public transport line to the Košice Airport (Fig. 1), chip card readers are used. Their location is not very convenient with regard to the passengers who purchase their tickets by using their chip cards; thus when boarding the vehicle, the passengers are held up in the door area. When a larger number of passengers board the bus, major delays occur. Such delays considerably affect the vehicle stopping time and, consequently, delays occur.

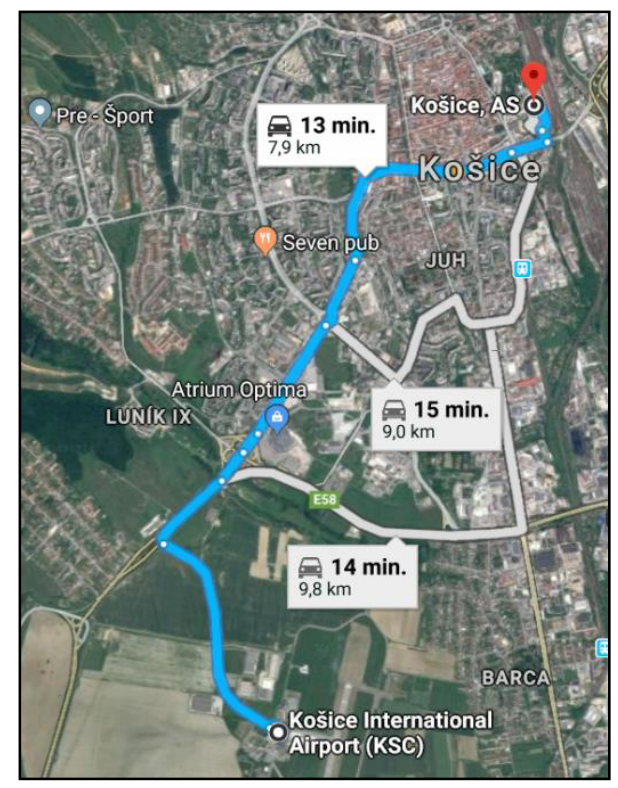

Fig. 1. The route of a Košice-Airport-bound shuttle.

\section{Suggested Solution}

In the present paper, two solutions verified by the Extend simulation program are given.

\subsection{Adding validators to the vehicle}

This suggestion presupposes adding further three validators, which would accelerate the boarding of passengers because they would not have to validate their tickets in the door area upon boarding, but later on in the vehicle. The proposed location of validators is illustrated in Fig. 2. 


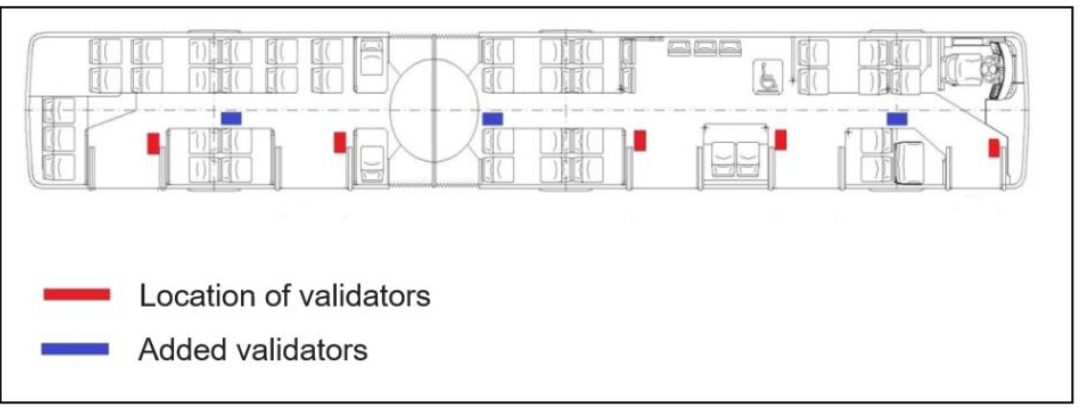

Fig. 2. Added validators in the vehicle.

\subsection{Adding door sensors}

The second suggestion considers locating card sensors at the vehicle door. The passengers passing a sensor would be identified without actually holding the chip card up to the sensor. In this way, it would be possible to purchase a ticket merely by boarding and leaving the vehicle without the option of actually selecting a ticket. Adding sensors presents a solution only when purchasing electronic tickets; thus, passengers who would prefer to validate a paper ticket would still do so using the validators in the door areas. The proposed placement of the added card sensors is given in Fig. 3.

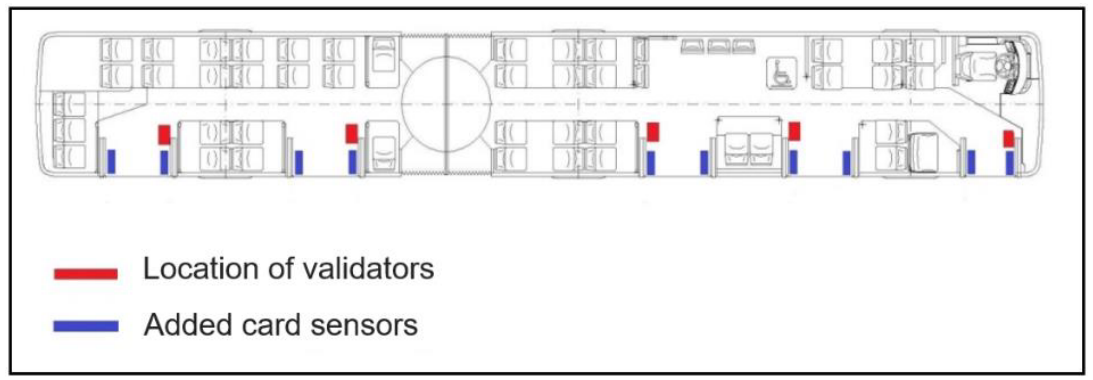

Fig. 3. Added card sensors to the door area.

\subsection{Verification of the Proposed Solutions by the Extend Simulation Program}

The Extend simulation program is used as one of many programs for the verification of available solutions prior to their implementation. In individual models, identical number of passengers boarding the vehicle and identical time during which they were held up at the readers were given.

In order to achieve comparable results, the number of 100 passengers boarding the vehicle and the hold-up of two seconds were stated for each model.

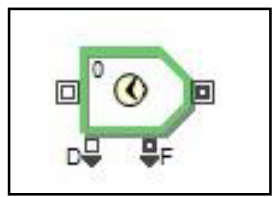

Fig. 4. Activity Block. 
The Activity block (Fig. 4) was used as a ticket validator in order to simulate each proposed solution; the delay was set to $2 \mathrm{sec}$.

\subsubsection{Simulation of the current state}

The first model simulates the existing state of one validator located at one door. One activity block having the function of a ticket validator was assigned to each vehicle door. The Resource Item Block in the simulation model generated a total of 100 passengers who passed through the Activity Block as they boarded the vehicle. The passengers passed through this block randomly, thus a different number of passengers passed through each Activity Block. The result of this simulation model is the time during which all 100 passengers boarded the vehicle provided that the vehicle was equipped with 5 validators and provided that each passenger validated a ticket. The result of the graph in Fig. 5 shows that the given number of passengers boarded the vehicle in 76 seconds.

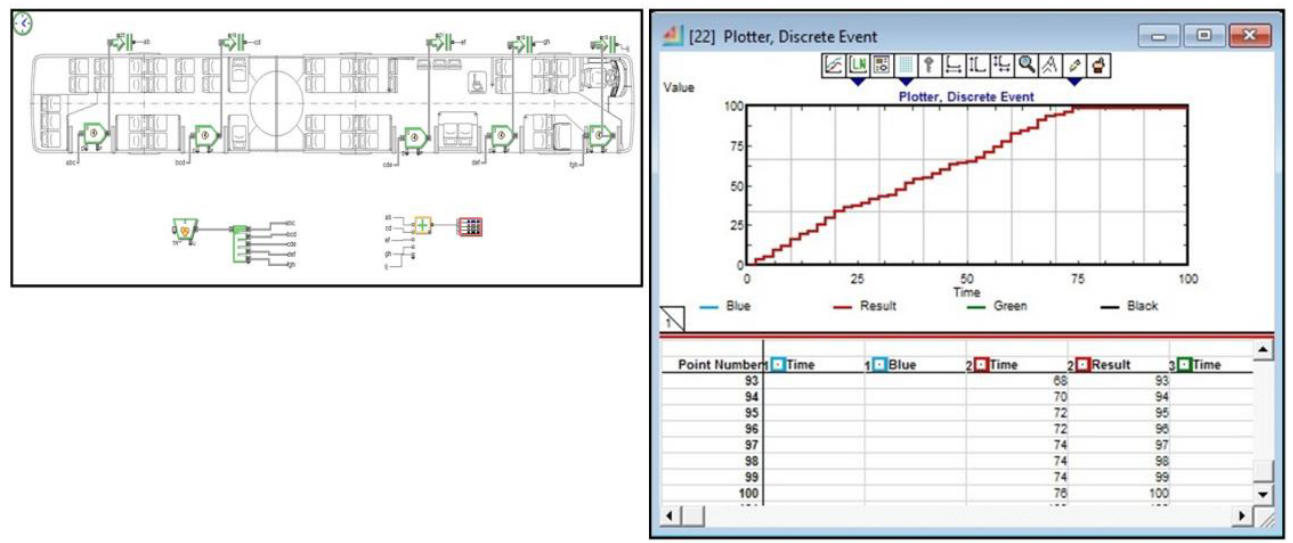

Fig. 5. Simulation model and the resulting graph simulating a regular number of validators.

\subsubsection{Simulation model with added validators in the vehicle}

In this simulation model, three ticket validators were added to the vehicle. They were added at the rear part of the vehicle between the next-to-last and the last doors, to the articulation section of the vehicle, and also between the first and the second doors where, after boarding the vehicle, the majority of passengers move after boarding the bus through the first door. If the passengers did not validate their tickets immediately after boarding the vehicle and did so only after moving on to the vehicle, the boarding time would be reduced when compared to the first model situation. By adding the three validators to the vehicle, the passengers' boarding time has been reduced. The simulation result in the graph in Fig. 6 illustrates the reducing of the passengers' boarding time to $62 \mathrm{~s}$. 

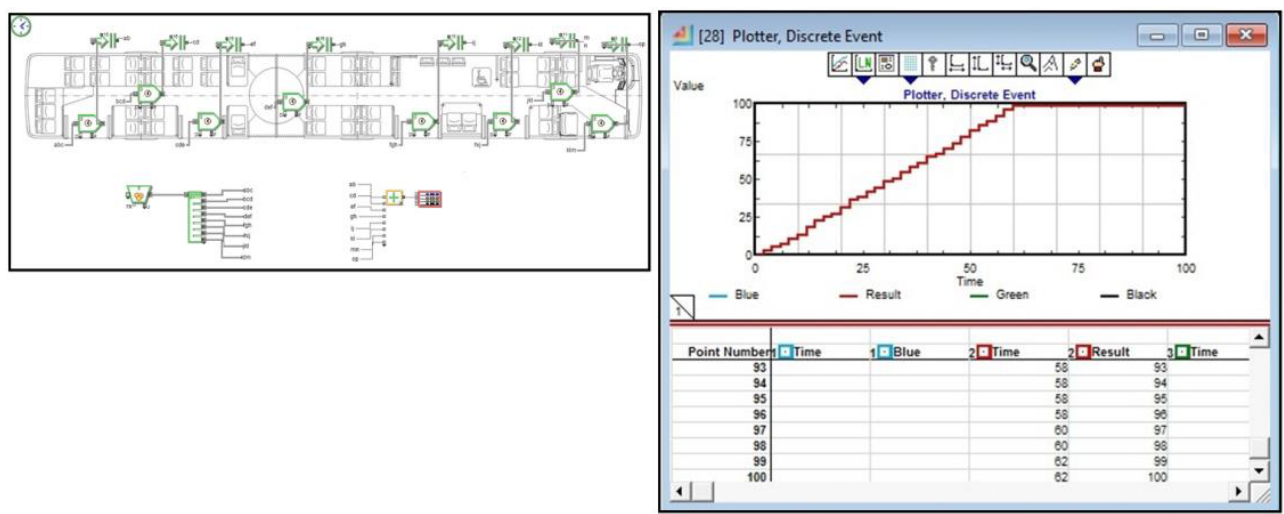

Fig. 6. Simulation model and the resulting graph with added validators to the vehicle.

\subsubsection{Simulation model with added sensors to the vehicle door}

At each door, the card chip sensor automatically records the passengers boarding the vehicle. The passengers would thus have a regular ticket validator at their disposal if they did not have an electronic ticket purchased by their smart card through the door sensor. The result of this model situation shown in the graph in Fig. 7 illustrates that the passengers boarded the vehicle in 56 seconds. In this case, boarding the vehicle was faster thanks to the sensors that automatically recorded the passengers passing by.
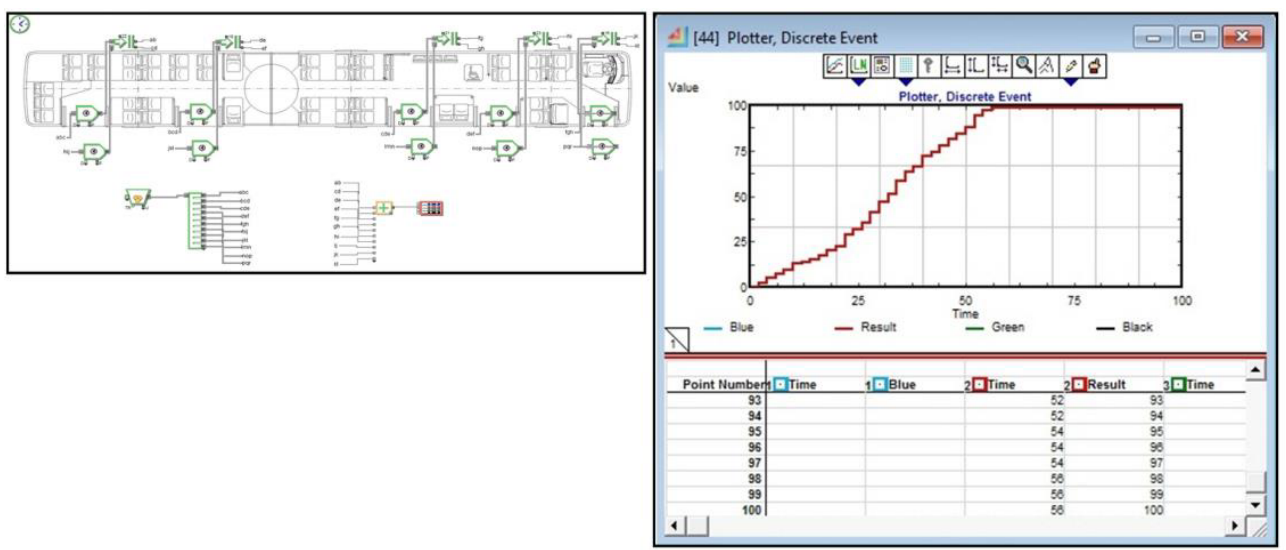

Fig. 7. Simulation model and the resulting graph with the sensors added to the door area.

\section{Conclusion}

The best solution after verification by the simulation program is the installation of card sensors in the door area. In this case, boarding the vehicle was the fastest.

By simulation, it was possible to model a variety of other types of boarding, to modify passengers' hold-up time at the validators and also to consider the possibility of a failure of any of the vehicle's validators/readers.

The present paper is a part of research grant projects VEGA 1/0063/16, VEGA 1/0403/18, KEGA 018TUKE-4/2016. 


\section{References}

1. G. Szendrö, Á. Török, Transport 29, pp. 12-17 (2014)

2. D.A. Hensher, Res. Transp. Econ. 18 (2007)

3. D. Bissell, Environ. Plan. D Soc. Sp. 28, pp. 270-289 (2010)

4. M.M. Rohani, D.C. Wijeyesekera, A.T.A. Karim, Procedia Eng., pp. 167-178 (2013)

5. N. Paulley, R. Balcombe, R. Mackett, H. Titheridge, J. Preston, M. Wardman, J. Shires, P. White, Transp. Policy 13, pp. 295-306 (2006)

6. R. Buehler, J. Pucher, Transp. Policy 18, pp. 126-138 (2011)

7. W.T. Lai, C.F. Chen, Transp. Policy 18, pp. 318-325 (2011)

8. O. Cats, F.M. Rufi, H.N. Koutsopoulos, Public Transp. 6, pp. 215-235 (2014)

9. W. Daamen, Modelling Passenger Flows in Public Transport Facilities ( Delft University Press Science, 2004)

10. M. Telecký, J. Čejka, M. Guchenko. Logi. 9, p. 105-113 DOI: https://doi.org/10.2478/logi-2018-0012 (2018)

11. L. Bartuska, K. Jerabek, L. Chenguang. Communications, 9, p. 103-108. ISSN 13354205. (2017)

12. L. Bartuska, V. Biba, R. Kampf. Proceedings of the Third International Conference on Traffic and Transport Engineering (Scientific Research Center Ltd. Belgrade, 2016) 